\title{
Efficacy and Effect of Inhaled Adenosine Treatment in Hospitalized COVID-19 Patients
}

\section{OPEN ACCESS}

Edited by:

Jean-Marc Cavaillon

Institut Pasteur, France

Reviewed by:

Harry Karmouty Quintana, University of Texas Health Science Center at Houston, United States Jayantha Arnold,

University of Buckingham, United Kingdom

Abdulla Abu-Bakr Badawy, Cardiff Metropolitan University, United Kingdom

*Correspondence: Lorenzo Romano Iorenzo.romano1177@gmail.com

tThese authors have contributed equally to this work

Specialty section:

This article was submitted to Inflammation,

a section of the journal

Frontiers in Immunology

Received: 01 October 2020 Accepted: 24 February 2021

Published: 18 March 2021

Citation:

Caracciolo M, Correale P, Mangano C,

Foti G, Falcone C, Macheda S,

Cuzzola M, Conte M, Falzea AC,

Iuliano E, Morabito A, Caraglia M,

Polimeni N, Ferrarelli A, Labate D, Tescione M, Di Renzo L, Chiricolo G, Romano $L$ and De Lorenzo A (2021)

Efficacy and Effect of Inhaled Adenosine Treatment in Hospitalized COVID-19 Patients.

Front. Immunol. 12:613070 doi: 10.3389/fimmu.2021.613070

\begin{abstract}
Massimo Caracciolo ${ }^{1 \dagger}$, Pierpaolo Correale ${ }^{2 \dagger}$, Carmelo Mangano ${ }^{3 t}$, Giuseppe Foti ${ }^{3}$, Carmela Falcone ${ }^{4}$, Sebastiano Macheda 5 , Maria Cuzzola ${ }^{6}$, Marco Conte 6 , Antonella Consuelo Falzea ${ }^{2}$, Eleonora luliano ${ }^{2}$, Antonella Morabito ${ }^{7}$, Michele Caraglia ${ }^{8,9}$, Nicola Polimeni ${ }^{5}$, Anna Ferrarelli ${ }^{4}$, Demetrio Labate ${ }^{5}$, Marco Tescione ${ }^{5}$, Laura Di Renzo ${ }^{10}$, Gaetano Chiricolo ${ }^{11}$, Lorenzo Romano ${ }^{12 *}$ and Antonino De Lorenzo ${ }^{10}$
\end{abstract}

${ }^{1}$ Unit of Post-Surgery Intensive Therapy (USDO), Grand Metropolitan Hospital, Reggio Calabria, Italy, ${ }^{2}$ Medical Oncology Unit, Grand Metropolitan Hospital, Reggio Calabria, Italy, ${ }^{3}$ Unit of Infectious Disease, Grand Metropolitan Hospital, Reggio Calabria, Italy, ${ }^{4}$ Unit of Radiology, Grand Metropolitan Hospital, Reggio Calabria, Italy, ${ }^{5}$ Unit of Intensive Care Medicine and Anaesthesia, Grand Metropolitan Hospital, Reggio Calabria, Italy, ${ }^{6}$ Microbiology Unit, Grand Metropolitan Hospital, Reggio Calabria, Italy, ${ }^{7}$ Unit of Pharmacy, Grand Metropolitan Hospital, Reggio Calabria, Italy, ${ }^{8}$ Department of Precision Medicine, University of Campania "L. Vanvitelli", Naples, Italy, ${ }^{9}$ Biogem Scarl, Institute of Genetic Research, Laboratory of Precision and Molecular Oncology, Ariano Irpino, Italy, ${ }^{10}$ Section of Clinical Nutrition and Nutrigenomics, Department of Biomedicine and Prevention, University of Rome Tor Vergata, Rome, Italy, ${ }^{11}$ Department of Biomedicine and Prevention, University of Rome Tor Vergata, Rome, Italy, ${ }^{12} \mathrm{PhD}$ School of Applied Medical, Surgical Sciences, University of Rome Tor Vergata, Rome, Italy

Lack of specific antiviral treatment for COVID-19 has resulted in long hospitalizations and high mortality rate. By harnessing the regulatory effects of adenosine on inflammatory mediators, we have instituted a new therapeutic treatment with inhaled adenosine in COVID-19 patients, with the aim of reducing inflammation, the onset of cytokine storm, and therefore to improve prognosis. The use of inhaled adenosine in COVID19 patients has allowed reduction of length of stay, on average 6 days. This result is strengthened by the decrease in SARS-CoV-2 positive days. In treated patients compared to control, a clear improvement in $\mathrm{PaO}_{2} / \mathrm{FiO}_{2}$ was observed together with a reduction in inflammation parameters, such as the decrease of CRP level. Furthermore, the efficacy of inhaled exogenous adenosine led to an improvement of the prognosis indices, NLR and PLR. The treatment seems to be safe and modulates the immune system, allowing an effective response against the viral infection progression, reducing length of stay and inflammation parameters.

Keywords: adenosine, COVID-19, SARS-CoV-2, length of stay, inflammation

\section{INTRODUCTION}

A new pandemic, Coronavirus disease 2019 (COVID-19), caused by severe acute respiratory syndrome following infection with the Severe acute respiratory syndrome coronavirus 2 (SARS-CoV-2) virus, hit the world starting in December $2019(1,2)$.

COVID-19 has shown an unexpected long incubation that has allowed the virus to be carried. Additionally, SARS-CoV-2 has shown the ability to trigger severe and inappropriate immune-inflammatory response in about $17-20 \%$ of infected individuals. This in turn may lead to highly lethal conditions including systemic micro-vascular damage with multiorgan failure and the dreaded acute respiratory distress syndrome (ARDS) which presents a $50 \%$ lethality rate (3). 
After the outbreak of the SARS-CoV-2, extensive researches were conducted to find common associations with SARS-CoV. In the viral genome, the 5 terminal portion encodes nonstructural proteins involved in some viral processes, and the remaining part encodes structural and accessory proteins, $\mathrm{S}$ (Spike), E (Envelope), M (Membrane) and N (Nucleocapsid) (4). Structural trimeric protein $\mathrm{S}$, composed of domains associated with different functions, such as virus entry and host tropism, determines the corona layer and the name of the virus. Through the ectodomain, composed of the S1 and S2 subunits, respectively receptor-binding and membrane-fusion domains, the virus interacts with specific receptors of the host target tissues (5).

SARS-CoV-2 hits different target organs, and mainly affects the lungs, small intestine and arterial smooth muscle cells, due to the increased expression of angiotensin converting enzyme 2 (ACE) (6), a zinc-containing metalloenzyme, which promotes viral infection (7). Furthermore, a possible bond between S1 viral subunit and host's Neuropillin-1 has recently been studied (8).

Therefore, within the infected population, COVID-19 can be asymptomatic or it can present multiple grades of severity and a wide spectrum of organ specific clinical manifestations as mildly asymptomatic, with fever, cough, fatigue, and intestinal symptoms; severely symptomatic, with progressive respiratory failure, pneumonia, ARDS, up to multiple organ failure and death $(1,9)$.

Recently, other clinical features have been described, including coagulopathies (due to reduced levels of platelets and fibrinogen), higher levels of lactate dehydrogenase (LDH), aspartate aminotransferase (AST) and alanine aminotransferase (ALT) whose role within the intraindividual clinical evolution of COVID-19 and its severity still need to be clarified (10).

The comorbidities, such as obesity, hypertension, chronic lung disease, diabetes mellitus, kidney disease, and cardiovascular disease, complicate the clinical course of COVID-19 (11).

Patients with obesity co-morbidities are more exposed to an evolution in ARDS from COVID-19, with fraction of inspired

\footnotetext{
Abbreviations: A2AR, adenosine $2 \mathrm{~A}$ receptors; $\mathrm{A} 2 \mathrm{BR}$, adenosine $2 \mathrm{~B}$ receptors; ACE, angiotensin converting enzyme 2; ALT, alanine aminotransferase; AR, adenosine receptors; ARDS, acute respiratory distress syndrome; AST, aspartate aminotransferase; B, B lymphocyte; BMI, body mass index; cAMP, cyclic AMP; CG, control group; CKF, chronic kidney failure; COPD, chronic obstructive pulmonary disease; COVID-19, coronavirus disease 2019; CREB, reactive element of cAMP; CRP, C-reactive protein; CT, computer tomography; CTL, cytotoxic; $\mathrm{FiO}_{2}$, inspired oxygen fraction; GGT, gamma-glutamyl transpeptidase; GOM, grande ospedale metropolitano; HCQ, hydroxychloroquine; ICU, intensive care unit; IFN- $\alpha$, interferon- $\alpha$; Ig, immunoglobulin g; IL, interleukin; INF- $\gamma$, interferon-gamma; $\mathrm{LDH}$, lactate dehydrogenase; LoS, length of stay; LPS, Lipopolysaccharide; mAb, monoclonal antibodies; MCP-1, monocyte chemoattractant protein-1; MERS$\mathrm{CoV}$, Middle East respiratory syndrome-related coronavirus; MERS-CoV, middle east respiratory syndrome coronavirus; $\mathrm{MHC}$, major histocompatibility class; MI, myocardial infarction; NFKB, nuclear factor kappa-light-chain-enhancer of activated B cells; NK, natural killer cell; NLR, neutrophils to lymphocytes; $\mathrm{PaCO}_{2}$, arterial carbon dioxide partial pressure; $\mathrm{PaO}_{2}$, arterial oxygen partial pressure; $\mathrm{PaO}_{2} / \mathrm{FiO}_{2}$, arterial oxygen partial pressure and fractional inspired oxygen ratio; PLR, platelet to lymphocyte; RBC, red blood cell; RdRp, RNA-dependent RNA polymerase; SARS-CoV-2, severe acute respiratory syndrome coronavirus 2; T, T lymphocyte; TCR, T-cell receptor-mediated signaling; TCZ, Tocilizumab; TG, treated group; Th, T helper; TLR, toll-like receptor; TNF, tumor necrosis factor; TNF- $\alpha$, tumor necrosis factor alpha; WBC, white blood cell.
}

oxygen $\left(\mathrm{FiO}_{2}\right)$ lower than $60 \%$, need for mechanical ventilation and intensive care unit (ICU) hospitalization (12).

Dramatically, over $50 \%$ of COVID-19 patients needed respiratory support due to an excessive pro-inflammatory response, with a massive release of interleukins (IL)- $1 \beta$, IL6 and Tumor Necrosis Factor (TNF)- $\alpha$, chemokines (13) and anti-inflammatory cytokines (1).

When there is a hyper-inflammatory state with maladaptive release of cytokines, the "cytokine storm" occurs, affecting mainly the lungs. The name is borrowed for its homologies with a similar clinical condition described in cancer patients under immunological treatment with cytokines (high does IL-2 and IL-12), costimulatory molecules (anti-CD28) and immunecheckpoint inhibitors (14).

This phenomenon had previously been observed also with SARS-CoV, involving IFN- $\gamma$ and IL-18 (15). The overproduction of IL- 6 can increase the risk of cardiovascular diseases, with high levels of hepatic C-reactive protein (CRP) (16).

Several reports suggest that the dysfunctional inflammatory process and the uncoordinated release of cytokines can severely compromise the innate or the humoral immunity. Therefore, the immune-surveillance system may not mount an efficient response to SARS-Cov-2 able to clear the infection, and to maintain an immunological lasting memory (17).

Furthermore, the onset of the cytokine storm compromises the antiviral response with a malfunctioning innate immune response. Natural killer cells, monocytes and macrophages as the first line of defense, predispose to the development of severe pneumonia, due to the alteration of Interferon levels (18).

The altered immune response, together with elevated levels of proinflammatory molecules as IL-1B, IFN- $\gamma$, IL-12, IFN$\gamma$, and chemokines have already been observed in infections from SARS-CoV and Middle East respiratory syndrome-related coronavirus (MERS-CoV) $(1,19)$. Similarly, increased monocyte chemoattractant protein-1 (MCP-1) was observed for all three viruses. This leads to activation and recall of monocytes, modulation of the Th1 mediated response and increase in the expression of inflammatory related Th2 markers (observed only in SarS-CoV2) (1).

Many therapies already in use against COVID-19, have been applied as potential treatments and can be grouped into the two categories of antiviral and immune-based therapies (20). Against SARS-CoV-2 infection, hydroxychloroquine (HCQ) and chloroquine, approved in emergency by the FDA last March, have been tested in several clinical studies (21) but the study reported by Self et al. in Journal of American Medical Association on November 9, 2020 did not show any significant improvement in clinical status in a well-designed placebo-controlled study (22).

Other potential treatments have been tested, many of them under study. These include two protease inhibitors, lopinavir and the more recent darunavir, both already in use against HIV-1 (23).

The combination lopinavir/ritonavir, designed for HIV, inhibits the aspartic protease, while the SARS-CoV-2 possesses a protease 3CLpro acting as cysteine protease. This undermines the effectiveness of the treatment $(23,24)$ but could lay the groundwork for the design of more active molecules (24). The 
effects of the combined use of lopinavir/ritonavir with other treatments was controversial and of less relevance as observed in the randomized studies (25).

Promising initial studies to have shown modest efficacy. There was a reduction in recovery time, from a median of 15 days among placebo recipients to 11 days among those receiving remdesivir, and it may have prevented progression to a more severe degree of respiratory disease $(26,27)$.

Immune-based therapies include monoclonal antibodies (mAb), such as Tocilizumab (TCZ), a humanized mAb acting on the IL-6 receptor (IL-6R), already used for autoimmune diseases (28). In COVID-19, the high release of IL-6 by T lymphocytes contributes to the cytokine storm. Consequently, TCZ competing for the IL-6R minimizes the inflammatory response to prevent possible respiratory insufficiency and ARDS, due to the involvement of the alveolar respiratory membrane (29).

Additional therapies such as anti-IL1 $\beta$, Canakinumab and Janus kinase inhibitors (JAK) $-1 / 2$ (Baricitinib and Ruxolitinib) have been tried out. However, to date, there is insufficient data to support their use $(30,31)$.

Due to paucity of approved therapies and a well-recognized anti-inflammatory action of adenosine, its application in COVID-19 has been hypothesized. The marked ability to inhibit inflammation is known from ischemia and reperfusion models. Therefore, adenosine has the potential act in acute lung injury as a local anti-inflammatory, also stemming the cytokine storm (32-34).

Adenosine exerts its action through the interaction with four subtypes of adenosine receptors (AR) (35). AR signaling occurs through the pathways of adenylate cyclase, phospholipase C, $\mathrm{Ca}^{+}$and mitogen-activated protein kinase $(36,37)$. Among the various effects of adenosine, the anti-inflammatory action is mainly mediated by the AR $2 \mathrm{~A}$ subtype. This receptor is primarily localized on immune cells, such as lymphocytes, monocytes, macrophages, and dendritic cells. AR 2A activation attenuates inflammatory processes and reperfusion damage inhibiting inflammatory cytokines and activated immune cells (38). Furthermore, in the lung tissue, it improves the functions of the capillary alveolar barrier, restoring physiological gas exchanges. Finally, adenosine-AR 2 A coupling is hypothesized to reduce T-cell receptor-mediated (TCR) production of IFN- $\gamma$, modulating the activation of $\mathrm{T}$ cells and secondary macrophages (39). It is hypothesized that in acute inflammation it may improve the inflammatory and immune response of the host against COVID-19 (40).

The aim of this case-control study is to evaluate the potential improvement in outcome, clinical characteristics and prognosis of hospitalized COVID-19 patients after treatment with aerosolized adenosine at the dosage of $9 \mathrm{mg}$ every $12 \mathrm{~h}$ in the first $24 \mathrm{~h}$ and subsequently, every $24 \mathrm{~h}$ for 5 days.

The primary endpoints are reduction of length of stay (LoS) and improvement of prognosis. The secondary endpoints are the reduction of inflammation severity, and timing of lung lesions by chest Computer Tomography (CT).

\section{MATERIALS AND METHODS}

\section{Study Assessments and Procedures}

The study population was represented by hospitalized native COVID-19 patients meeting eligibility criteria.

This single-center case-control study involved off-label treatment with adenosine, administered to Sars-CoV2 positive patients, who arrived at the Emergency Department of the "Bianchi Melacrino Morelli" Grande Ospedale Metropolitano (GOM) of Reggio Calabria, Italy, between March 19 and April 13, 2020.

After Sars-CoV2 positivity confirmation, patients were transferred to the Infectious Diseases Unit, underwent chest CT, drug therapy with low molecular weight heparin, azithromycin, HCQ, and lopinavir/ritonavir.

At baseline, after interrupting Lopinavir/ritonavir administration, biochemical-clinical analyses were performed to all eligible patients and off-label treatment was started in the treated group (TG), represented by the patients who accepted compassionate treatment. The control group (CG) included eligible patients, with characteristics homogenous to TG, who did not accept the off-label compassionate use of Adenosine.

The following additional information was collected (41): myocardial infarction (MI); atrial fibrillation; type 2 diabetes mellitus; chronic liver disease; chronic obstructive pulmonary disease (COPD); chronic kidney failure (CKF); stroke; cancer in the last 5 years.

At 10 days from baseline, patients underwent follow-up of blood chemistry and clinical parameters.

On the 21st day after admission to the Infectious Diseases Unit, all patients underwent a chest CT-scan.

The off-label treatment was administered after obtaining informed consent and approval for each patient from the Hospital Safety Team.

All patients' history and clinical status data were collected at baseline and follow up. All chest CT scans, SarS-CoV2 research, and blood chemistry analyses were performed at the GOM.

Days of SarS-CoV2 positivity are evaluated from the first positive test to the second negative test in $48 \mathrm{~h}$. In addition, hospitalization days were examined from transfer to the Infectious Diseases Unit until discharge. The discharge was allowed with two negative SarS-CoV2 tests within $48 \mathrm{~h}$ and remission of clinical symptoms. Timeline of progress from admission to discharge is showed in Figure 1. The study was approved by the Ethics Committee of Southern Calabria (April 30, 2020). The privacy and sensitive data of patients have been protected and the database can be consulted on the IT System of GOM, after appropriate authorization (direzionesanitaria@ospedalerc.it), according to the GDPR UE 2016/679.

Inclusion criteria:

- Biologically confirmed by SARS-CoV-2 PCR test.

- COVID-19 diagnosis clinically and radiologically confirmed by chest CT scan.

Exclusion criteria: 


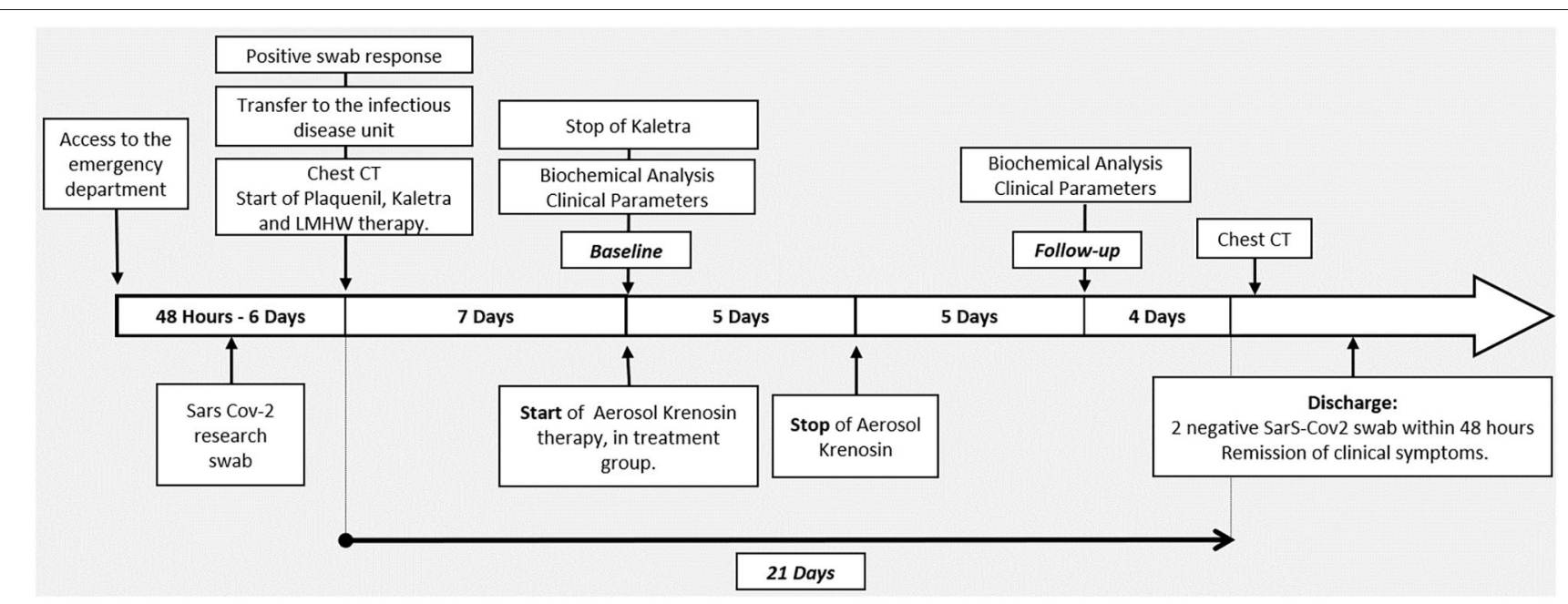

FIGURE 1 | Timeline of progress from admission to discharge.

- Patients with a history of neutropenia.

- Patients with acquired immunodeficiency.

- Patients with cancer history in the last 5 years.

- Patients who underwent transplants.

- Patients who received previous immunosuppressive therapies or corticosteroids.

- Women who are pregnant or breastfeeding.

\section{Withdrawal Criteria}

Participants were free to withdraw from participation in the study at any time upon request or at the request of their legally acceptable representative.

An investigator may discontinue or withdraw a participant from the study for the following reasons:

- Pregnancy

- Non-compliance to study intervention

- Occurrence of any clinical adverse event, laboratory abnormality, or medical condition compromising continued participation in the study and not in the best interest of the participant.

- Severe side effects clearly related to the study device.

- Disease progression requiring other treatments.

- If the participant meets an exclusion criterion (either newly developed or not previously recognized) that precludes further study participation

- Participant unable to receive study intervention for $>$ 2 days/week.

- Subject non-compliant to investigational procedures.

- Subject non-compliant to visits.

\section{Therapy}

All patients received standard therapeutic protocol including low molecular weight heparin 4,000 units two times a day, azithromycin 1 tablet a day when needed, HCQ (Plaquenil ${ }^{\circledR}$ ) $200 \mathrm{mg}, 2$ tablets two times a day, lopinavir/ritonavir (Kaletra ${ }^{\circledR}$ ) $100 / 25 \mathrm{mg}, 2$ tablets two times a day for 7 days (42).
Respiratory support was used when needed, according to current guidelines.

The off-label treatment involved the use of inhaled adenosine (Krenosin $\AA$ ), $9 \mathrm{mg}$ every $12 \mathrm{~h}$ for the first $24 \mathrm{~h}$ and subsequently, every $24 \mathrm{~h}$ for 4 days $(43,44)$. Nebulized adenosine was delivered

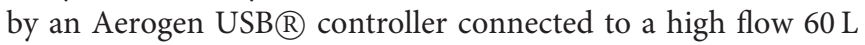
for $5 \mathrm{~min}$ device, with $21 \% \mathrm{FiO}_{2}$. The safe posology has been established from preclinical studies $(45,46)$.

The administration of aerosolized adenosine has a doselimiting efficacy $>10 \mathrm{mg}$. Its use did not show adverse effects in non-asthmatic subjects $(47,48)$.

Adverse effects were monitored throughout the study and patients underwent continuous monitoring of cardiocirculatory and respiratory function.

\section{Sars-CoV2 Swab Test}

SARS-CoV-2 was detected by RNA sequencing assay (Seegene Allplex $^{\mathrm{TM}}$ 2019-CoV Assay, catalog number \#RP10243X 100 rxn), targeting SARS-CoV-2 RdRp, E and N genes. Data were analyzed by CFX96 Manager software and Seegene viewer software. The responses were "2019-nCoV detected," "negative," or "invalid" (Allplex 2019-nCoV assay IFU) (49).

\section{Anthropometry}

The Body Mass Index (BMI) was calculated by weight and height measured, according to Romano et al. (50) or referred when unable to carry out the assessment.

\section{Biological Specimen Collection and Laboratory Evaluations}

The following blood analysis were performed at each evaluation time: blood gas analysis parameters, as arterial oxygen partial pressure $\left(\mathrm{PaO}_{2}\right)$ and arterial carbon dioxide partial pressure $\left(\mathrm{PaCO}_{2}\right)$; fractional inspired oxygen $\left(\mathrm{FiO}_{2}\right)$ in patients with respiratory support; arterial oxygen partial pressure and fractional inspired oxygen ratio $\left(\mathrm{PaO}_{2} / \mathrm{FiO}_{2}\right)$ (51); platelets 
$\left(10^{3} / \mu \mathrm{L}\right)$; white blood cells (WBC) $\left(10^{3} / \mu \mathrm{L}\right)$; red blood cells (RBC) $\left(10^{6} / \mu \mathrm{L}\right)$; hemoglobin $(\mathrm{g} / \mathrm{dL})$; neutrophils $\left(10^{3} / \mu \mathrm{L}\right)$; lymphocytes $\left(10^{3} / \mu \mathrm{L}\right)$; monocyte $\left(10^{9} / \mathrm{L}\right)$; fibrinogen $(\mathrm{mg} / \mathrm{dL})$; D-dimer (ng/mL); CRP $(\mathrm{mg} / \mathrm{L})$; glycemia (mg/dL); albumin (g/dL); AST (U/L); HALT (U/L); gamma-glutamyl transpeptidase (GGT); indirect bilirubin ( $\mathrm{mg} / \mathrm{dL})$; direct bilirubin $(\mathrm{mg} / \mathrm{dL})$; amylase (U/L); lipase (U/L); potassium (mEq/L); sodium (mEq/L). According to Qin, neutrophils to lymphocytes (NLR) and platelet to lymphocyte (PLR) were calculated (52).

\section{Chest CT and Findings}

CT examination was performed with high-resolution acquisitions for the study of lung interstitium, with CT GE Medical System Optima CT 660, followed by multi-parametric reconstructions according to coronal and sagittal and $3 \mathrm{D}$ plans.

Two radiologists independently and blindly examined the Chest CT scans and reported the radiographic findings, according to Chung (53).

\section{Statistical Analysis}

All statistical analyses were conducted with SPSS 23 software (version 23.0, IBM, Armonk, NY, USA). Data collected before statistical evaluations were analyzed for the presence of outliners and for normally distribution with the Shapiro-Wilk test. The data presented are expressed as mean, standard deviation, percentage in contingency tables and as $\Delta \%$, to evaluate differences between the times. Before, the differences between CG and TG patients were assessed by Independent samples $t$-test and Mann Whitney test. Subsequently, the two-tailed Student's paired $t$-test or Wilcoxon rank test were used to assess the presence of differences in the variables examined between baseline and follow-up. Conclusively, for each study variable, to compare the trend over time, $\Delta \%$ were calculated equal to the percentage variation of each parameter calculated as an absolute margin of variation from the baseline value. The differences in $\Delta \%$ between baseline and follow-up among groups were assessed with the ANOVA one-way test. The presence of difference in contingency tables were analyzed with the Chi square test. Statistical significance was set to a value of $p<0.05$. All $p$-values shown are two-tailed.

\section{RESULTS}

Of the 30 Caucasian patients enrolled for prospective analytical case-control study, 6 subjects were excluded from the study for the following reasons: 2 subjects did not meet inclusion criteria (transfer in intensive care unit), 1 subject died before starting treatment; 3 subjects were excluded for incomplete data. Finally, 24 patients were included in the study. The age of subjects was $56.86 \pm 15.65$ years, $37.50 \%$ females and $62.50 \%$ males. The eligible patients were allocated into two groups: 12 patients in the CG (41.67\% females and $58.33 \%$ males) and 12 patients in the treatment group (TG) $(33.33 \%$ females and $66.67 \%$ males). As reported in Figure 2, it was observed that the days of hospitalization and test positivity were statically decreased in TG compared to CG (respectively $p=0.032$; $p=0.002$ ). As reported in Table 1, No statistical differences between groups were observed in age, BMI, days of HDCL and AZT treatment. At baseline, only PLR was statistically increased in TG compared to CG $(p=0.004)$. Lymphocytes and potassium were significantly reduced in TG compared to CG (respectively $p=0.021 ; p=0.022$ ). No other statistical differences between groups were detected. As reported in Table 2, at baseline no statistical differences were observed in the frequency of airway support, hypertension, diabetes mellitus and dementia. Furthermore, none of the enrolled patients suffered from COPD,

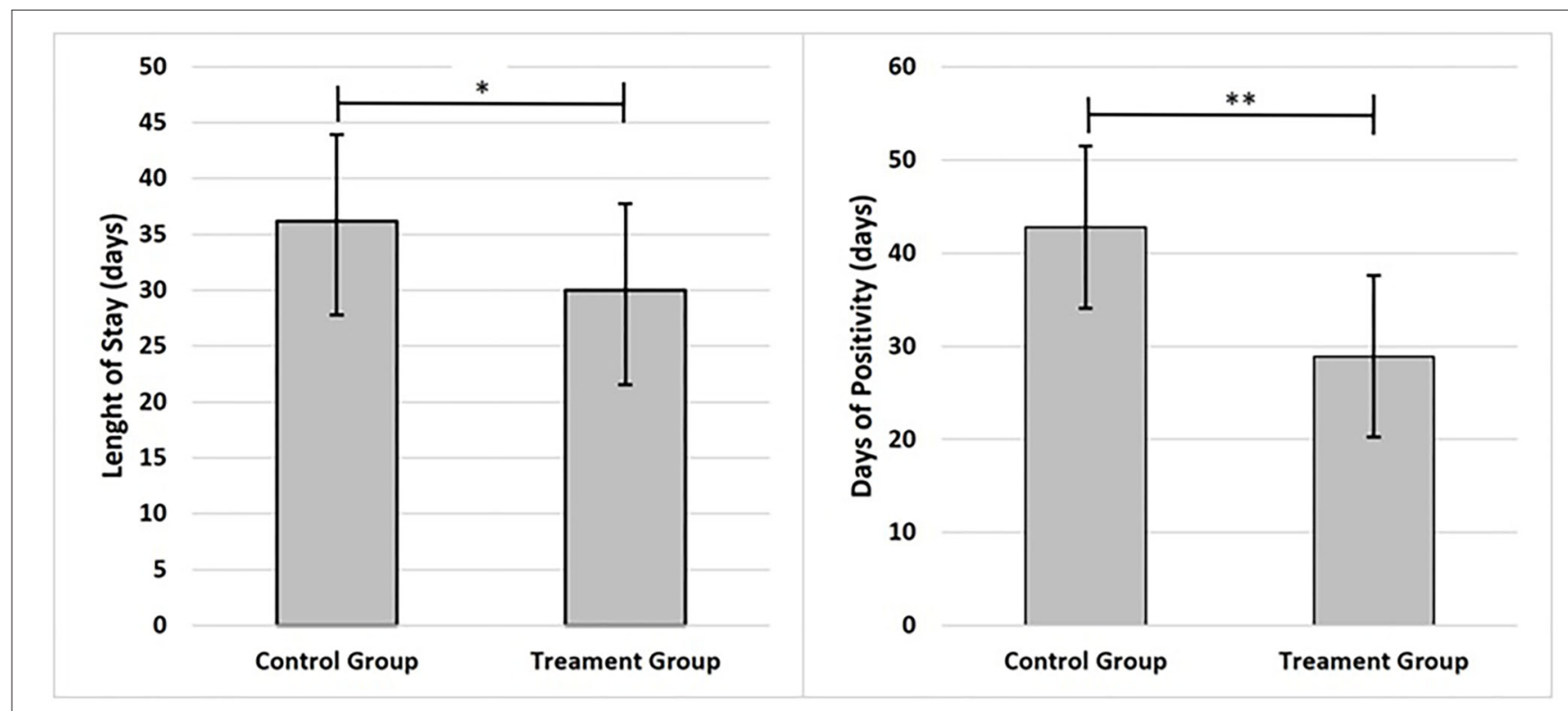

FIGURE 2 | Graphs present main results; data are shown as mean and standard deviation \pm 1 . Statistical significance was attributed as ${ }^{\star \star} p<0.05 ;{ }^{* \star} p<0.01$. 
TABLE 1 | Differences between control group and treatment group at baseline.

\begin{tabular}{|c|c|c|c|}
\hline Parameters & $\begin{array}{l}\text { Control group } \\
\text { Means } \pm \text { SD }\end{array}$ & $\begin{array}{l}\text { Treatment group } \\
\text { Means } \pm \text { SD }\end{array}$ & $p$ \\
\hline Age (years) & $58.80 \pm 15.84$ & $54.92 \pm 16.90$ & 0.578 \\
\hline Days HDCL & $11.50 \pm 3.89$ & $10.11 \pm 3.30$ & $0.922^{*}$ \\
\hline Days AZT & $11.50 \pm 5.96$ & $11.11 \pm 4.26$ & $0.767^{\star}$ \\
\hline \multicolumn{4}{|l|}{ Baseline } \\
\hline $\mathrm{BMI}\left(\mathrm{kg} / \mathrm{m}^{2}\right)$ & $30.08 \pm 5.02$ & $31.59 \pm 3.74$ & 0.427 \\
\hline NLR & $4.32 \pm 3.94$ & $7.14 \pm 8.86$ & $0.644^{*}$ \\
\hline PLR & $94.03 \pm 84.58$ & $305.17 \pm 166.07$ & $0.004^{*}$ \\
\hline $\mathrm{PaO}_{2}(\mathrm{mmHg})$ & $86.20 \pm 17.12$ & $79.25 \pm 12.01$ & 0.351 \\
\hline $\mathrm{PaCO}_{2}(\mathrm{mmHg})$ & $39.20 \pm 4.76$ & $42.08 \pm 11.73$ & $0.670^{*}$ \\
\hline $\mathrm{FiO}_{2}(\%)$ & $0.31 \pm 0.12$ & $0.29 \pm 0.12$ & $0.655^{\star}$ \\
\hline $\mathrm{PaO}_{2} / \mathrm{FiO}_{2}$ & $304.35 \pm 109.35$ & $315.67 \pm 123.06$ & $0.916^{\star}$ \\
\hline $\operatorname{RBC}\left(10^{3} / \mu \mathrm{L}\right)$ & $4.85 \pm 0.38$ & $4.43 \pm 0.73$ & 0.110 \\
\hline Hemoglobin (g/dL) & $13.65 \pm 1.73$ & $13.23 \pm 2.39$ & 0.644 \\
\hline Platelets $\left(10^{3} / \mu \mathrm{L}\right)$ & $147.52 \pm 126.17$ & $230.92 \pm 122.42$ & 0.132 \\
\hline WBC $\left(10^{3} / \mu \mathrm{L}\right)$ & $8.78 \pm 4.41$ & $5.58 \pm 2.94$ & 0.055 \\
\hline Neutrophils $\left(10^{3} / \mu \mathrm{L}\right)$ & $6.25 \pm 4.57$ & $3.98 \pm 3.10$ & 0.183 \\
\hline Lymphocytes $\left(10^{3} / \mu \mathrm{L}\right)$ & $1.74 \pm 0.63$ & $1.01 \pm 0.72$ & 0.021 \\
\hline C-reactive Protein (mg/L) & $59.13 \pm 76.79$ & $49.70 \pm 47.71$ & $0.927^{\star}$ \\
\hline Glycemia (mg/dL) & $107.3 \pm 13.71$ & $99.58 \pm 14.11$ & 0.211 \\
\hline Albumin (g/dL) & $4.01 \pm 0.47$ & $3.82 \pm 0.63$ & 0.435 \\
\hline Sodium (mEq/L) & $135.8 \pm 4.89$ & $134.58 \pm 4.29$ & 0.542 \\
\hline Potassium (mEq/L) & $4.28 \pm 0.52$ & $3.80 \pm 0.38$ & 0.022 \\
\hline AST (U/L) & $34.6 \pm 27.35$ & $53.67 \pm 43.60$ & $0.284^{\star}$ \\
\hline ALT (U/L) & $42.50 \pm 31.11$ & $59.50 \pm 56.02$ & $0.767^{\star}$ \\
\hline GGT (U/L) & $43.50 \pm 26.69$ & $38.17 \pm 29.03$ & $0.468^{\star}$ \\
\hline Indirect bilirubin (mg/dL) & $0.64 \pm 0.39$ & $0.91 \pm 0.77$ & $0.262^{*}$ \\
\hline Direct bilirubin (mg/dL) & $0.27 \pm 0.09$ & $0.23 \pm 0.14$ & $0.552^{\star}$ \\
\hline Amylase (U/L) & $87.2 \pm 44.34$ & $76.92 \pm 43.84$ & $0.322^{*}$ \\
\hline Lipase (U/L) & $178.5 \pm 193.15$ & $143.42 \pm 105.84$ & 1.00 \\
\hline Fibrinogen (mg/dL) & $554.00 \pm 265.23$ & $459.25 \pm 231.85$ & 0.448 \\
\hline D-Dimer (ng/mL) & $736.20 \pm 564.55$ & $346.67 \pm 309.91$ & 0.083 \\
\hline
\end{tabular}

All parameters are presented as mean \pm standard deviation, they were compared by Independent samples $t$-test and (*) Mann Whitney test, statistical significance was attributed as $p<0.05$.

$S D$, standard deviation; BMI, body mass index; HDCL, hydroxychloroquine; $A Z T$, azithromycin; $\mathrm{PaO}_{2}$, arterial oxygen partial pressure; $\mathrm{PaCO}_{2}$, arterial carbon dioxide partial pressure; $\mathrm{FiO}$, fractional inspired oxygen; $\mathrm{PaO}_{2} / \mathrm{FiO}$, arterial oxygen partial pressure and fractional inspired oxygen ratio; NLR, neutrophils and lymphocytes ratio; $P L R$, platelets and lymphocytes ratio; RBC, red blood cells; WBC, white blood cells; AST, aspartate aminotransferase; ALT, alanine aminotransferase; GGT, gamma-glutamyl transpeptidase.

CKF, MI and cancer in the past 5 years. As reported in Table 3, between baseline and follow-up, it was observed that NLR, $\mathrm{RBC}$, hemoglobin and neutrophils were statically reduced in CG (respectively $p=0.028 ; p=0.032 ; p=0.032 ; p=0.038$ ), the $\mathrm{PaO}_{2} / \mathrm{FiO}_{2}$, platelets and lipase concentration were statically increased in CG $(p=0.042 ; p=0.038 ; p=0.037)$. Between baseline and follow-up, NLR, PLR, $\mathrm{FiO}_{2}, \mathrm{CRP}$, amylase, lipase and $\mathrm{D}$-dimer concentration were statistically decreased in TG (respectively $p=0.008 ; p=0.003 ; p=0.042 ; p=0.005 p=0.025$; $p=0.042 ; p=0.020) ; \mathrm{PaO}_{2}, \mathrm{PaO}_{2} / \mathrm{FiO}_{2}$ and lymphocytes were significantly increased in TG (respectively $p=0.045 ; p=0.014$;
TABLE 2 | Contingency of the respiratory support, Azithromycin (AZT) and comorbidity and needs at baseline.

\begin{tabular}{|c|c|c|c|c|c|}
\hline & \multicolumn{4}{|c|}{ Group } & \\
\hline & & Control & Treatment & Tot & \\
\hline \multirow[t]{3}{*}{ Airways support } & No (\%) & 27.30 & 31.75 & 59.05 & \\
\hline & Yes (\%) & 18.20 & 22.75 & 40.95 & $x^{2}=0.006$ \\
\hline & Tot (\%) & 45.50 & 54.50 & 100.00 & $p=0.640$ \\
\hline \multirow[t]{3}{*}{$\mathrm{AZT}$} & No (\%) & 22.75 & 31.75 & 54.50 & \\
\hline & Yes (\%) & 22.75 & 22.75 & 45.50 & $x^{2}=0.067$ \\
\hline & Tot (\%) & 45.50 & 54.50 & 100.00 & $p=0.560$ \\
\hline \multirow[t]{3}{*}{ Hypertension } & No (\%) & 22.75 & 40.90 & 63.60 & \\
\hline & Yes (\%) & 22.75 & 13.60 & 36.35 & $x^{2}=1.470$ \\
\hline & Tot (\%) & 45.50 & 54.50 & 100.00 & $p=0.221$ \\
\hline \multirow[t]{3}{*}{ Diabetes mellitus } & No $(\%)$ & 31.80 & 50.00 & 81.80 & \\
\hline & Yes (\%) & 13.70 & 4.50 & 18.10 & $x^{2}=1.720$ \\
\hline & Tot (\%) & 45.50 & 54.50 & 100.00 & $p=0.225$ \\
\hline \multirow[t]{3}{*}{ Dementia } & No (\%) & 41.00 & 50.00 & 91.00 & \\
\hline & Yes (\%) & 4.50 & 4.50 & 9.00 & $x^{2}=0.180$ \\
\hline & Tot (\%) & 45.50 & 54.50 & 100.00 & $p=0.745$ \\
\hline
\end{tabular}

The data are shown as percentages. Among groups, the presence of difference in aspect ratio was analyzed with the Chi square test, statistical significance was attributed as $p<0.05$.

$p=0.013)$. Moreover, PLR and CRP showed a greater significant $\Delta \%$ reduction in TG (respectively $p=0.017 ; p=0.046$ ). It was observed that $\Delta \% \mathrm{PaO}_{2} / \mathrm{FiO}_{2}$ was significantly raised in TG $(p=0.046)$ and $\Delta \%$ platelets in CG $(p=0.013)$ (Table 3$)$. In Table 4, qualitative changes in CT findings are reported. It was observed that ground-glass opacities or consolidation and pleural effusion frequencies were overall, and in each group, statically reduced (respectively $p=0.002 ; p=0.021 ; p=0.021$ and $p=0.007 ; p=0.021 ; p=0.048$ ). Ground-glass opacities with consolidation, rounded morphology and pneumopathy $>25 \%$ frequencies were significantly decreased in overall and TG (respectively $p=0.012 ; p=0.045 ; p=0.023 ; p=0.012 ; p=0.041$ and $p=0.048)$. More than two lobes affected, and bilateral lung disease frequencies were statistically increased in CT $(p=0.035)$. Pneumopathy frequencies was observed statically reduced only in overall $(p=0.029)$.

\section{DISCUSSION}

The use of inhaled adenosine in COVID19 patients has allowed reduction of LoS, on average 6 days. This result is strengthened by the decrease in SARS-CoV-2 positive days. In TG patients compared to CG, a clear improvement in $\mathrm{PaO}_{2} / \mathrm{FiO}_{2}$, Horowitz index, was observed together with a reduction in inflammation parameters, such as the decrease of CRP level. In addition, an improvement in lymphopenia as a result of reduced inflammation was highlighted. Furthermore, the presumed efficacy of inhaled exogenous adenosine led to an improvement of the prognosis indices, NLR and PLR. This result was confirmed by the reduction in LoS. 
TABLE 3 | Differences between baseline and follow-up in each group.

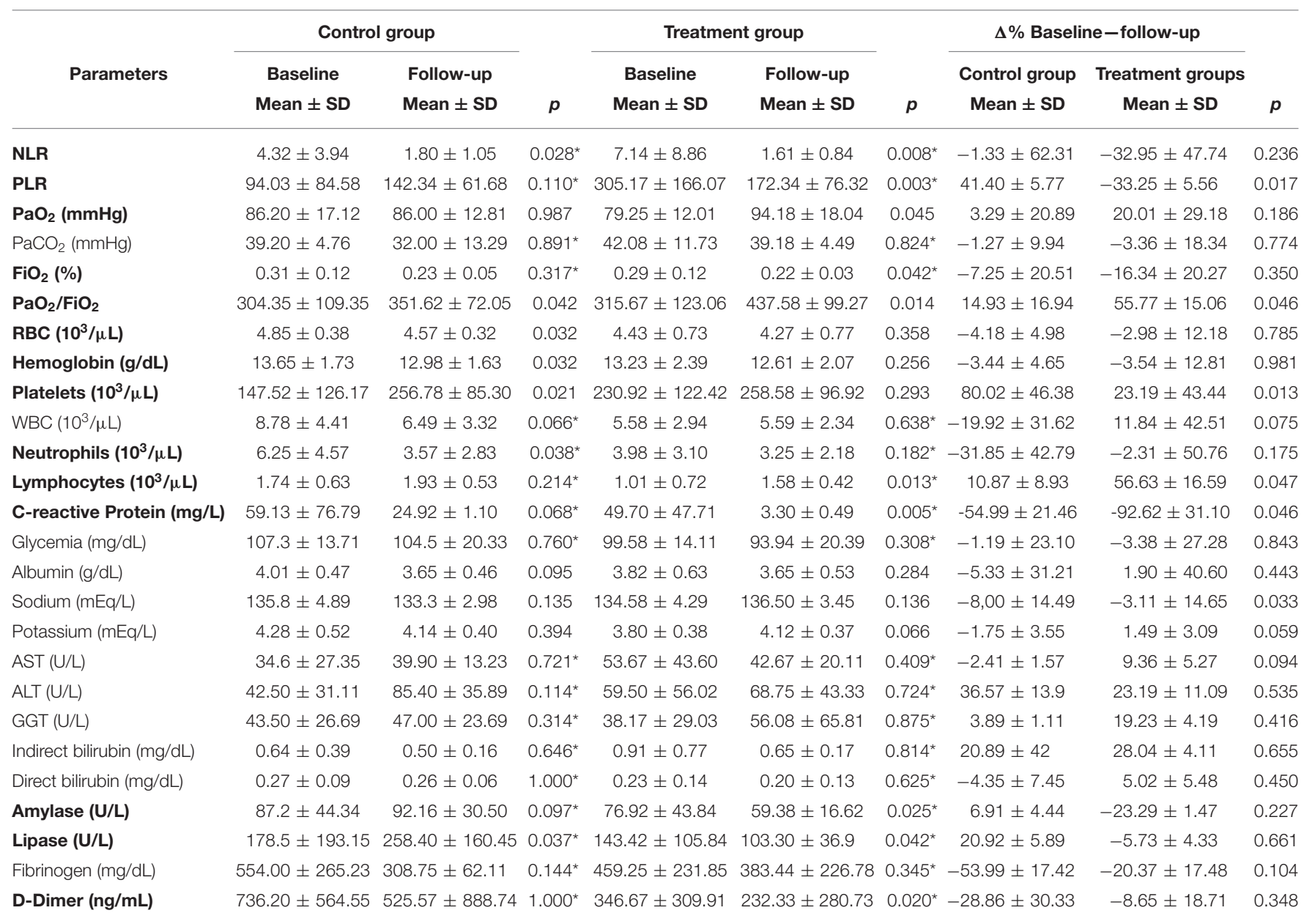

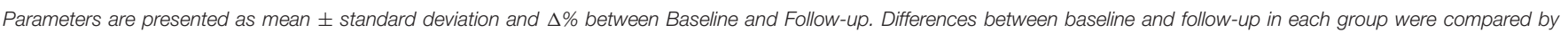

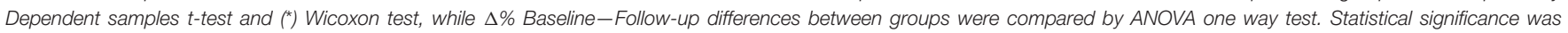

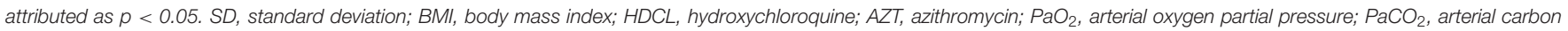

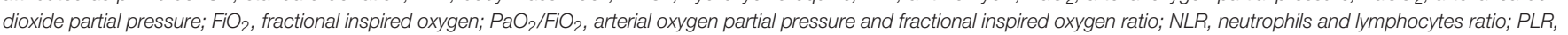

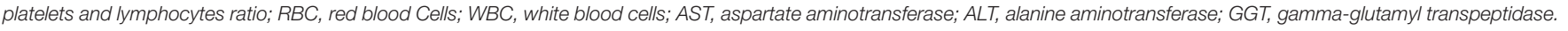

In spite of specific antiviral treatment and recent availability of preventative vaccine for COVID-19, large numbers of patients are still being admitted with long hospitalizations and high mortality rate, two of the main drivers of major public health concerns. In COVID-19, lopinavir/ritonavir did not show an improvement in the mortality rate.

Indeed, several treated patients had to discontinue treatment due to gastrointestinal side effects. Also, the randomized study on treatment with TCZ, administered at an early stage, ended prematurely due to the absence of benefit in terms of aggravation and survival (54). Again, on November 20th, the WHO pointed out that there is not enough evidence to support its use. Indeed, regardless of disease severity, remdesivir only has conditional recommendation for use in COVID 19 (55).

Besides, no significant differences in clinical status or overall mortality were observed between patients treated with convalescent plasma and those who received placebo (56).
By harnessing the regulatory effects of adenosine on inflammatory mediators, we have instituted a new therapeutic treatment with inhaled adenosine in COVID-19 patients, with the aim of reducing inflammation, the onset of cytokine storm, and therefore to improve prognosis.

At baseline, patients showed no differences between the two groups in terms of age, BMI, standard therapy duration, and respiratory parameters. Furthermore, no differences were observed in the anamnestic data and in the use of respiratory support. LoS reduction, one of the two primary outcomes, was observed in TG and between groups the difference was approximately of 6 days. This result affects the clinical, economic, and social aspect. In addition, decreased risk of complications, the psychological impact and the consequent recovery after hospitalization are highlighted (57).

Given the emergency, isolated hospitalization, far from relatives and in absence of the usual physician-patient 
TABLE 4 | Table contingency of qualitative change after 21 days in finding CT.

\begin{tabular}{|c|c|c|c|c|c|c|c|c|c|c|c|c|}
\hline Parameters & \multicolumn{4}{|c|}{ Overall } & \multicolumn{4}{|c|}{ Control group } & \multicolumn{4}{|c|}{ Treatment group } \\
\hline Ground-glass opacities or consolidation & 64.29 & 0.00 & 9.95 & 0.002 & 83.33 & 0.00 & 5.33 & 0.021 & 50.00 & 0.00 & 5.33 & 0.021 \\
\hline Ground-glass opacities without consolidation & 28.57 & 50.00 & 1.34 & 0.246 & 0.00 & 33.33 & 2.40 & 0.121 & 50.00 & 62.50 & 0.25 & 0.614 \\
\hline Ground-glass opacities with consolidation & 50.00 & 7.14 & 6.30 & 0.012 & 66.67 & 16.67 & 3.08 & 0.079 & 37.50 & 0.00 & 3.70 & 0.045 \\
\hline \multicolumn{13}{|l|}{ Lobes affected } \\
\hline More than two lobes affected & 42.86 & 64.29 & 0.70 & 0.403 & 0.00 & 83.33 & 5.33 & 0.035 & 75.00 & 50.00 & 1.07 & 0.302 \\
\hline Bilateral lung disease & 42.86 & 78.57 & 0.00 & 1.000 & 0.00 & 83.33 & 5.33 & 0.035 & 75.00 & 75.00 & 0.00 & 1.000 \\
\hline \multicolumn{13}{|l|}{ Frequency of lobe involvement } \\
\hline Right upper lobe & 71.43 & 57.14 & 0.62 & 0.430 & 83.33 & 66.67 & 0.44 & 0.505 & 62.50 & 50.00 & 0.25 & 0.614 \\
\hline \multicolumn{13}{|l|}{ Opacification distribution and pattern } \\
\hline Rounded morphology & 71.43 & 28.57 & 5.14 & 0.023 & 50.00 & 33.33 & 0.34 & 0.558 & 87.50 & 25.00 & 6.34 & 0.012 \\
\hline Linear opacities & 42.86 & 57.14 & 1.47 & 0.225 & 0.00 & 66.67 & 0.44 & 0.505 & 75.00 & 50.00 & 1.07 & 0.302 \\
\hline Crazy-paving pattern & 21.43 & 0.00 & 3.36 & 0.067 & 33.33 & 0.00 & 2.40 & 0.121 & 12.50 & 0.00 & 1.07 & 0.302 \\
\hline Cavitation & 7.14 & 7.14 & 0.00 & 1.000 & 0.00 & 0.00 & $/ /$ & $/ /$ & 12.50 & 12.50 & 0.00 & 1.000 \\
\hline \multicolumn{13}{|l|}{ Other findings } \\
\hline Discrete pulmonary nodules & 64.29 & 28.57 & 3.60 & 0.058 & 83.33 & 50.00 & 1.50 & 0.221 & 50.00 & 12.50 & 2.62 & 0.106 \\
\hline Pleural effusion & 64.29 & 14.29 & 7.33 & 0.007 & 83.33 & 16.67 & 5.33 & 0.021 & 50.00 & 12.50 & 3.29 & 0.048 \\
\hline Pneumopathy $>25 \%$ & 71.43 & 35.71 & 3.56 & 0.041 & 83.33 & 50.00 & 1.50 & 0.221 & 62.50 & 25.00 & 3.29 & 0.048 \\
\hline Pneumopathy > 50\% & 42.86 & 7.14 & 4.72 & 0.029 & 66.67 & 16.67 & 3.08 & 0.079 & 25.00 & 0.00 & 2.29 & 0.131 \\
\hline
\end{tabular}

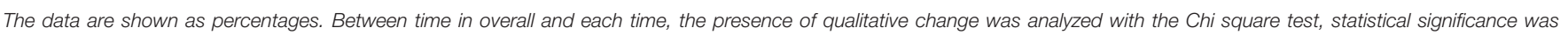
attributed as $p<0.05$.

relationship, had a negative impact on psycho-physical health $(49,58)$. The reduction of positive days to Sars-CoV2 is a significant finding that confirms the above-mentioned results. In fact, TG patients showed a negative detection of SarS-CoV2 approximately 11 days sooner. LoS only included the stay in Infectious Disease Department, while positivity days also included hospitalization in the Emergency Department. In TG, the LOS exceeds the positive period of 1 day, this is due to the waiting of clinical recovery.

At baseline, severe lymphopenia, leukopenia, elevated levels of CRP, D-Dimer, lipase, and amylase were present in both groups, clinical features already observed in other studies (59-62). In TG, lymphopenia was higher in comparison to CG, with a consequent higher PLR. As already observed by Chen et al. (63) and by our group, lymphopenia is a feature present in symptomatic patients and with severe COVID-19. The high production of cytokines and inflammation leads to a decrease in $\mathrm{T}$ lymphocytes proliferation and exhaustion of their immunological profile (64). Probably, an unresponsive lymphocyte function is the host countermeasure to prevent mass immune activations and consequent tissue damage. Finally, we hypothesize that some clinical differences at baseline are attributable to the heterogeneity of patients who had access to the GOM in the emergency phase.

As Wang et al. (62) signs of pancreatic distress were observed, a common feature with previous Sars-CoV infection. In fact, the ACE2 is expressed in the intestine and pancreas $(65,66)$. In addition to the cytopathic effect induced by viral replication, the pancreatic insult could be caused by the action of the immune system in response to lung and systemic inflammation (62).

At follow-up, the results showed a general improvement in clinical conditions, inflammatory and respiratory parameters in both groups, a course linked to the disease $(9,67,68)$. In both groups, an improvement in the $\mathrm{PaO}_{2} / \mathrm{FiO}_{2}$ ratio was observed. However, the TG showed greater improvements. At the same time, a reduction of oxygen therapy administered and a significant increase in $\mathrm{PaO}_{2}$ was observed in $\mathrm{TG}$. When comparing the groups, $\Delta \%$ of $\mathrm{PaO}_{2} / \mathrm{FiO}_{2}$ confirmed the effectiveness of the treatment with a significant increase of $55 \%$ for TG. The hypothesized beneficial effect of adenosine is observed from the improvement of lung function and from the signs of inflammatory decrease in TG. Alongside, increase in $\mathrm{PaO}_{2} / \mathrm{FiO}_{2}$, a significant reduction in $\mathrm{C}$-reactive protein, a resumption of lymphocyte count and a reduction in D-Dimer 
levels were observed. Similar results were seen in patients treated with Acalabrutinib, an inhibitor of the Bruton tyrosine kinase enzyme (69).

The adenosine effectiveness could be attributed to the modulating and regulatory activity on macrophages. In fact, signs of macrophage activation syndrome were observed in CG, such as an increase in CRP, inflammatory cytokines (70) and the predominant presence of monocytes/macrophages in the pulmonary alveoli, observed in post-mortem analyses (71).

In patients with COVID-19 obesity and related diseases has been found to be more common, depicting a higher inflammatory "Starting Point" determining activation and dysregulation of macrophages $(72,73)$. Proper functioning of the innate immune system allows for the rapid recognition and elimination of pathogens (74). In COVID 19, the presence of a dysregulated immune response $(17,67)$ with a proinflammatory imbalance, an excessive recruitment of monocytes, macrophages and overproduction of cytokines and inflammatory molecules has been observed in some cases $(75,76)$.

It can be hypothesized that those events determine the pulmonary macrophage activation syndrome and, in some cases, the systemic trigger of the cytokine storm.

In this process, adenosine administered by inhalation helps regulating inflammation through its receptors, $\mathrm{A} 2 \mathrm{~A}$ and $\mathrm{A} 2 \mathrm{~B}$ expressed in macrophages, neutrophils, monocytes, lymphocytes and platelets (77-79).

We hypothesized that the treatment is aimed at restoring the signaling mediated by A2A and A2B AR and therefore increasing the protection of healthy lung tissue by increasing the protective capacity of the respiratory epithelial barrier and reducing the damage induced by overactivation of the immune system. From this perspective, there is broad agreement that mechanical lung damage associated with active ventilation may add to SARS-CoV2 -induced lung damage. On the other hand, it is now widely known that the abuse of hyperoxic respiration itself can inhibit the main physiological protective mechanism of hypoxia-A2adenosinergic which leads to massive consequences of tissue damage (80).

It has been shown that extracellular accumulation of adenosine can contribute to regulating inflammation, immunity, and tissue repair (75).

Through A2A, adenosine determines the differentiation of an anti-inflammatory dendritic phenotype that promotes TH2 lymphocytes, inhibition of T-cell receptor signaling and generation of regulatory TH17 (81). Furthermore, the activation of $\mathrm{A} 2 \mathrm{~B}$ leads to the inhibition of activating macrophages with inhibition of the release of TNF- $\alpha$, IL-6 and IL-12, increasing the production of the anti-inflammatory molecule IL-10 (82).

In addition, a significant decrease in D-dimer, an increase in circulating lymphocytes and a decrease in NLR and PLR were observed in TG. This is due to the reduction of inflammation, probably mediated by the treatment. The same improvements are not observed in the CG, but a reduction in the number of neutrophils is highlighted.

However, ours was a case control study and not a randomized double-blind study and lymphocyte count was lower in the treatment group before Adenosine was administered.
Therefore, firm conclusions cannot be drawn in comparison with the CG.

Since the NLR index is reduced in both CG and TG, it would not seem to be attributable to the treatment. Indeed, observing the terms of the NLR ratio, the reduction of neutrophils is observed in the CG, while in the TG there is a recovery of lymphopenia. Therefore, the result might seem the same but is linked to different inflammatory processes and to disease course.

Again, the observed reduction in TG of PLR is compatible with an improvement in the prognosis, which is then confirmed by the reduction in LoS (60).

At the follow-up, a worsening of pancreatic indices, in particular lipase was observed in CG. On the other hand, the opposite was observed in TG, with a significant improvement in both pancreatic enzymes. This could be explained by the reduction of lung and systemic inflammation and by pancreatic localization of adenosine receptors (83).

Regarding CT findings, reductions of ground-glass opacities with consolidation and rounded morphology were observed in TG. Then, pleural effusion and pneumopathy under the $50 \%$ reduction were observed. The radiological improvement supports the hypothesis of this study since there is a regression of inflammation and lung lesions.

Finally, adenosine use showed a good tolerance of the administered dose with no cardiovascular and respiratory side effects, confirming the safety of its use.

The hypothesis presented by Abouelkhair (84) on the use of drugs inhibiting adenosine formation and its pathways with the increase of ATP levels, does not find a rationale in the timing of administration.

In fact, with current knowledge it is difficult to understand when to administer these drugs. Therefore, compared to the previous hypothesis, the treatment and the route of administration we propose finds a good time of administration: the symptomatic patient and before clinical features of the onset of cytokine storm are seen.

Given the beneficial effects of adenosine in acute inflammation, we propose a new treatment for hospitalized COVID-19 patients, with the aim to prevent the cytokine storm, and therefore to improve the prognosis, and reducing LoS. The study was conducted as case-control but randomized controlledclinical trials on a larger population will be necessary to confirm our results (85). Limitations of this study include the lack of studies on involved molecular pathways, dosage of inflammation biomarkers, small sample size, and non-randomization, due to emergency and off-label treatment. The case-control study design limits the results interpretation. Thus, there is a definite necessity for a randomized multicenter study, which also involves the use of specific biomarkers useful for describing inflammatory responses."

Continuous chronic administration of inhaled adenosine has been demonstrated to give rise to the onset of fibrosis and pulmonary hypertension (32). These could be potential negative consequences, especially after a Sars-CoV-2 infection. Consequently, adenosine treatment was limited to 5 days to avoid development of fibrosis. Moreover, long-term monitoring was provided for these patients. 
Future research should also consider the evaluation of adenosine in ARDS patients. Also, it would be useful to introduce preclinical studies that take into consideration the entire immune profile for a full comprehension of underlying mechanisms, potentiality, and limits. Supportive evidence in theory has been published in two key papers. Oral Pentoxyfylline has a similar effect to inhaled adenosine in working via the A2 AR pathway to attenuate immune exuberance by increasing the secondary messenger Cyclic AMP in the A2 AR pathway beyond adenosine $(86,87)$.

In conclusion, the treatment seems to be safe and modulates the immune system, allowing an effective response against the progress of the viral infection, reducing LoS. In fact, a reduction in inflammation, resumption of immune response parameters, prognostic indices, clinical pulmonary and systemic improvement are reported. Furthermore, the hypothesis that the treatment leads to an improvement in the respiratory parameters a priori in COVID-19, due to a direct action on the respiratory tract (88), remains to be investigated.

\section{DATA AVAILABILITY STATEMENT}

The raw data supporting the conclusions of this article will be made available by the authors, without undue reservation.

\section{REFERENCES}

1. Huang C, Wang Y, Li X, Ren L, Zhao J, Hu Y, et al. Clinical features of patients infected with 2019 novel coronavirus in Wuhan, China. Lancet. (2020) 395:497-506. doi: 10.1016/S0140-6736(20)30183-5

2. Zhen-Dong Y, Gao-Jun Z, Run-Ming J, Zhi-Sheng L, Zong-Qi D, Xiong $\mathrm{X}$, et al. Clinical and transmission dynamics characteristics of 406 children with coronavirus disease 2019 in China: a review. J Infect. (2020) 81:e115. doi: 10.1016/j.jinf.2020.04.030

3. Mutti L, Pentimalli F, Baglio G, Maiorano P, Saladino RE, Correale $\mathrm{P}$, et al. Coronavirus disease (COVID-19): what are we learning in a country with high mortality rate? Front Immunol. (2020) 11:1208. doi: 10.3389/fimmu.2020.01208

4. Fehr AR, Perlman S. Coronaviruses: an overview of their replication and pathogenesis. Methods Mol Biol. (2015) 1282:123. doi: 10.1007/978-1-4939-2438-7_1

5. Li F. Structure, function, and evolution of coronavirus spike proteins. Annu Rev Virol. (2016) 3:237-61. doi: 10.1146/annurev-virology-110615-042301

6. Hofmann H, Pyrc K, van der Hoek L, Geier M, Berkhout B, Pöhlmann S. Human coronavirus NL63 employs the severe acute respiratory syndrome coronavirus receptor for cellular entry. Proc Natl Acad Sci USA. (2005) 102:7988-93. doi: 10.1073/pnas.0409465102

7. Hoffmann M, Kleine-Weber H, Schroeder S, Krüger N, Herrler T, Erichsen S, et al. SARS-CoV-2 Cell Entry Depends on ACE2 and TMPRSS2 and Is Blocked by a Clinically Proven Protease Inhibitor. Cell. (2020) 181:271-80.e8. doi: 10.1016/j.cell.2020.02.052

8. Daly JL, Simonetti B, Klein K, Chen KE, Williamson MK, Antón-Plágaro C, et al. Neuropilin-1 is a host factor for SARS-CoV-2 infection. Science. (2020) 370:861-5. doi: 10.1126/science.abd3072

9. Wang D, Hu B, Hu C, Zhu F, Liu X, Zhang J, et al. Clinical characteristics of 138 hospitalized patients with 2019 novel coronavirus-infected pneumonia in Wuhan, China. JAMA. (2020) 323:1061-9. doi: 10.1001/jama.2020.1585

10. Henderson LA, Canna SW, Schulert GS, Volpi S, Lee PY, Kernan KF, et al. On the alert for cytokine storm: immunopathology in COVID-19. Arthritis Rheumatol. (2020) 72:1059-63. doi: 10.1002/art.41285

\section{ETHICS STATEMENT}

The studies involving human participants were reviewed and approved by Ethics Committee of Southern Calabria (April 30, 2020). The patients/participants provided their written informed consent to participate in this study.

\section{AUTHOR CONTRIBUTIONS}

MCc, PC, and AD: conceptualization. LR: methodology. LDR and LR: formal analysis. MCc, PC, CM, GF, and SM: investigation. $\mathrm{CF}, \mathrm{MCu}, \mathrm{MCo}, \mathrm{ACF}, \mathrm{EI}, \mathrm{AM}, \mathrm{MCg}, \mathrm{NP}, \mathrm{AF}, \mathrm{DL}$, and MT: data curation. LDR, LR, and AD: writing-original draft preparation. LDR, GC, LR, and AD: writing-review and editing. LDR and LR: visualization. AD: supervision. All authors have read and agreed to the published version of the manuscript. Authorship must be limited to those who have contributed substantially to the work reported.

\section{ACKNOWLEDGMENTS}

The authors are grateful to the patients, to all healthcare professionals involved and to the General Manager Iole Fantozzi.

11. Garg S, Kim L, Whitaker M, O'Halloran A, Cummings C, Holstein R, et al. Hospitalization rates and characteristics of patients hospitalized with laboratory-confirmed coronavirus disease 2019-COVID-NET, 14 states, March 1-30, 2020. MMWR Morb Mortal Wkly Rep. (2020) 69:45864. doi: 10.15585/mmwr.mm6915e3

12. Fowler RA, Lapinsky SE, Hallett D, Detsky AS, Sibbald WJ, Slutsky AS, et al. Critically ill patients with severe acute respiratory syndrome. JAMA. (2003) 290:367-73. doi: 10.1001/jama.290.3.367

13. Lau SKP, Lau CCY, Chan K-H, Li CPY, Chen H, Jin D-Y. Delayed induction of proinflammatory cytokines and suppression of innate antiviral response by the novel Middle East respiratory syndrome coronavirus: implications for pathogenesis and treatment. J Gen Virol. (2013) 94:267990. doi: 10.1099/vir.0.055533-0

14. Shimabukuro-Vornhagen A, Gödel P, Subklewe M, Stemmler HJ, Schlößer HA, Schlaak M, et al. Cytokine release syndrome. J Immunother Cancer. (2018) 6:56. doi: 10.1186/s40425-018-0343-9

15. Huang KJ, Su IJ, Theron M, Wu YC, Lai SK, Liu CC, et al. An interferongamma-related cytokine storm in SARS patients. J Med Virol. (2005) 75:18594. doi: 10.1002/jmv.20255

16. Wilson AM, Ryan MC, Boyle AJ. The novel role of C-reactive protein in cardiovascular disease: risk marker or pathogen. Int J Cardiol. (2006) 106:2917. doi: $10.1016 /$ j.ijcard.2005.01.068

17. Tay MZ, Poh CM, Rénia L, MacAry PA, Ng L. The trinity of COVID19: immunity, inflammation and intervention. Nat Rev Immunol. (2020) 20:363-74. doi: 10.1038/s41577-020-0311-8

18. Channappanavar R, Fehr AR, Vijay R, Mack M, Zhao J, Meyerholz $\mathrm{DK}$, et al. Dysregulated type I interferon and inflammatory monocytemacrophage responses cause lethal pneumonia in SARS-CoV-infected mice. Cell Host Microbe. (2016) 19:181-93. doi: 10.1016/j.chom.2016. 01.007

19. Zhou J, Chu H, Li C, Wong BH, Cheng ZS, Poon VK, et al. Active replication of Middle East respiratory syndrome coronavirus and aberrant induction of inflammatory cytokines and chemokines in human macrophages: implications for pathogenesis. J Infect Dis. (2014) 209:133142. doi: 10.1093/infdis/jit504 
20. Kumari P, Rawat K, Saha L. Pipeline pharmacological therapies in clinical trial for COVID-19 pandemic: a recent update. Curr Pharmacol Rep. (2020) 1-13. doi: 10.1007/s40495-020-00226-5

21. Liu J, Cao R, Xu M, Wang X, Zhang H, Hu H, et al. Hydroxychloroquine, a less toxic derivative of chloroquine, is effective in inhibiting SARS-CoV-2 infection in vitro. Cell Discov. (2020) 6:16. doi: 10.1038/s41421-020-0156-0

22. Mauthe M, Orhon I, Rocchi C, Zhou X, Luhr M, Hijlkema KJ, et al. Chloroquine inhibits autophagic flux by decreasing autophagosome-lysosome fusion. Autophagy. (2018) 14: 1435-55. doi: 10.1080/15548627.2018.14 74314

23. Riva A, Conti F, Bernacchia D, Pezzati L, Sollima S, Merli S, et al. Darunavir does not prevent SARS-CoV-2 infection in HIV patients. Pharmacol Res. (2020) 157:104826. doi: 10.1016/j.phrs.2020.104826

24. Chen YW, Yiu CB, Wong KY. Prediction of the SARS-CoV-2 (2019$\mathrm{nCoV}$ ) 3C-like protease (3CL pro) structure: virtual screening reveals velpatasvir, ledipasvir, and other drug repurposing candidates. F1000Res. (2020) 9:129. doi: 10.12688/f1000research.22457.2

25. Cao B, Wang Y, Wen D, Liu W, Wang J, Fan G, et al. A trial of lopinavirritonavir in adults hospitalized with severe COVID-19. N Engl J Med. (2020) 382:1787-99. doi: 10.1056/NEJMoa2001282

26. Beigel JH, Tomashek KM, Dodd LE, Mehta AK, Zingman BS, Kalil AC, et al. Remdesivir for the treatment of COVID-19-final report. N Engl J Med. (2020) 383:1813-26. doi: 10.1056/NEJMoa2007764

27. Dolin R, Hirsch MS. Remdesivir-an important first step. NEngl J Med. (2020) 383:1886-7. doi: 10.1056/NEJMe2018715

28. Xu X, Han M, Li T, Sun W, Wang D, Fu B, et al. Effective treatment of severe COVID-19 patients with tocilizumab. Proc Natl Acad Sci USA. (2020)117:10970-5. doi: 10.1073/pnas.2005615117

29. Fu B, Xu X, Wei H. Why tocilizumab could be an effective treatment for severe COVID-19? J Transl Med. (2020) 18:164. doi: 10.1186/s12967-02002339-3

30. Michot JM, Albiges L, Chaput N, Saada V, Pommeret F, Griscelli F, et al. Tocilizumab, an anti-IL-6 receptor antibody, to treat COVID-19related respiratory failure: a case report. Ann Oncol. (2020) 31:9614. doi: 10.1016/j.annonc.2020.03.300

31. Caracciolo $\mathrm{M}$, Macheda $\mathrm{S}$, Labate $\mathrm{D}$, Tescione $\mathrm{M}$, La Scala $\mathrm{S}$, Vadalà E, et al. Case report: canakinumab for the treatment of a patient with COVID-19 acute respiratory distress syndrome. Front Immunol. (2020) 11:1942. doi: 10.3389/fimmu.2020.01942

32. Le TT, Berg NK, Harting MT, Li X, Eltzschig HK, Yuan X. Purinergic signaling in pulmonary inflammation. Front Immun. (2019) 10:1633. doi: 10.3389/fimmu.2019.01633

33. Wilson CN, Batra VK. Lipopolysaccharide binds to and activates A(1) adenosine receptors on human pulmonary artery endothelial cells. J Endotoxin Res. (2002) 8:263-71. doi: 10.1179/096805102125000470

34. Koeppen M, Eckle T, Eltzschig HK. Selective deletion of the A1 adenosine receptor 514 abolishes heart-rate slowing effects of intravascular adenosine in vivo. PLoS ONE. (2002) 4:e6784. doi: 10.1371/journal.pone.0006784

35. Yaar R, Jones MR, Chen JF, Ravid K. Animal models for the study of adenosine receptor function. J Cell Physiol. (2005) 202:9-20. doi: 10.1002/jcp. 20138

36. Sun CX, Young HW, Molina JG, Volmer JB, Schnermann J, Blackburn MR. A protective role for the Al adenosine receptor in adenosine-dependent pulmonary injury. J Clin Invest. (2005) 115:35-43. doi: 10.1172/JCI22656

37. Ohta A, Sitkovsky M. Role of G-protein-coupled adenosine receptors in downregulation of inflammation and protection from tissue damage. Nature. (2001) 414:916-20. doi: 10.1038/414916a

38. Sitkovsky MV, Lukashev D, Apasov S, Kojima H, Koshiba M, Caldwell C, et al. Physiological control of immune response and inflammatory tissue damage by hypoxia-inducible factors and adenosine A2A receptors. Annu Rev Immunol. (2004) 22:657-82. doi: 10.1146/annurev.immunol.22.012703.104731

39. Lappas CM, Rieger JM, Linden J. A2A adenosine receptor induction inhibits IFN-gamma production in murine CD4 ${ }^{+} \mathrm{T}$ cells. J Immunol. (2005) 174:1073-80. doi: 10.4049/jimmunol.174.2.1073

40. Bouma MG, Jeunhomme TM, Boyle DL, Dentener MA, Voitenok NN, van den Wildenberg FA, et al. Adenosine inhibits neutrophil degranulation in activated human whole blood: involvement of adenosine A2 and A3 receptors. J Immunol. (1997) 158:5400-8.
41. L'epidemiologia per la sanità pubblica. Istituto Superiore di Sanità Gli Studi interventistici per l'emergenza COVID-19. (2020). Available online at: https://www.epicentro.iss.it/coronavirus/sars-cov-2-analisi-studiinterventistici (accessed September 4, 2020).

42. Md Insiat Islam Rabby. Current drugs with potential for treatment of COVID-19: a literature review. J Pharm Pharm Sci. (2020) 23:5864. doi: $10.18433 /$ jpps31002

43. Correale P, Caracciolo M, Bilotta F, Conte M, Cuzzola M, Falcone $\mathrm{C}$, et al. Therapeutic effects of adenosine in high flow $21 \%$ oxygen aereosol in patients with COVID19-pneumonia. PLOS ONE. (2020) 15: e0239692. doi: 10.1371/journal.pone.0239692

44. Falcone C, Caracciolo M, Correale P, Macheda S, Vadalà EG, La Scala S, et al. Can adenosine fight COVID-19 acute respiratory distress syndrome? J Clin Med. (2020) 9:E3045. doi: 10.3390/jcm9093045

45. Aggarwal NR, D'Alessio FR, Eto Y, Chau E, Avalos C, Waickman AT, et al. Macrophage A2A adenosinergic receptor modulates oxygen-induced augmentation of murine lung injury. Am J Respir Cell Mol Biol. (2013) 48:635-46. doi: 10.1165/rcmb.2012-0351OC

46. Jacobson KA, Tosh DK, Jain S, Gao ZG. Historical and current adenosine receptor agonists in preclinical and clinical development. Front Cell Neurosci. (2019) 13:124. doi: 10.3389/fncel.2019.00124

47. Cushley MJ, Tattersfield AE, Holgate ST. Inhaled adenosine and guanosine on airway resistance in normal and asthmatic subjects. Br J Clin Pharmacol. (1983) 15:161-5. doi: 10.1111/j.1365-2125.1983.tb01481.x

48. van der Wiel E, Lexmond AJ, van den Berge M, Postma DS, Hagedoorn P, Frijlink HW, et al. Targeting the small airways with dry powder adenosine: a challenging concept. Eur Clin Respir J. (2017) 4:1369328. doi: 10.1080/20018525.2017.1369328

49. Gualtieri P, Falcone C, Romano L, Macheda S, Correale P, Arciello P, et al. Body composition findings by computed tomography in SARS-CoV2 patients: increased risk of muscle wasting in obesity. Int J Mol Sci. (2020) 21:4670. doi: 10.3390/ijms21134670

50. Romano L, Marchetti M, Gualtieri P, Di Renzo L, Belcastro M, De Santis GL, et al. Effects of a personalized VLCKD on body composition and resting energy expenditure in the reversal of diabetes to prevent complications. Nutrients. (2019) 11:1526. doi: 10.3390/nu11071526

51. ARDS Definition Task Force, Ranieri VM, Rubenfeld GD, Thompson BT, Ferguson ND, Caldwell E, et al. Acute respiratory distress syndrome: the Berlin definition. JAMA. (2012) 307:2526-33. doi: 10.1001/jama.2012.5669

52. Qin B, Ma N, Tang Q, Wei T, Yang M, Fu H, et al. Neutrophil to lymphocyte ratio (NLR) and platelet to lymphocyte ratio (PLR) were useful markers in assessment of inflammatory response and disease activity in SLE patients. Mod Rheumatol. (2016) 26:372-6. doi: 10.3109/14397595.2015.1091136

53. Chung M, Bernheim A, Mei X, Zhang N, Huang M, Zeng X, et al. CT imaging features of 2019 novel coronavirus (2019-nCoV). Radiology. (2020) 295:202-7. doi: 10.1148/radiol.2020200230

54. Toniati P, Piva S, Cattalini M, Garrafa E, Regola F, Castelli F, et al Tocilizumab for the treatment of severe COVID-19 pneumonia with hyperinflammatory syndrome and acute respiratory failure: a single center study of 100 patients in Brescia, Italy. Autoimmun Rev. (2020) 19:102568. doi: 10.1016/j.autrev.2020.102568

55. World Health Organization. (2020). WHO recommends against the use of remdesivir in COVID-19 patients. Available online at: https://www.who.int/ news-room/feature-stories/detail/who-recommends-against-the-use-ofremdesivir-in-covid-19-patients (accessed November 27, 2020).

56. Simonovich VA, Burgos Pratx LD, Scibona P, Beruto MV, Vallone MG, Vázquez $\mathrm{C}$, et al. A randomized trial of convalescent plasma in COVID-19 severe pneumonia. N Engl J Med. (2020) 384:61962. doi: 10.1056/NEJMoa2031304

57. Aubertin-Leheudre M, Rolland Y. The importance of physical activity to care for frail older adults during the COVID-19 pandemic. J Am Med Dir Assoc. (2020) 21:973-6. doi: 10.1016/j.jamda.2020.04.022

58. Epstein D, Andrawis W, Lipsky AM, Ziad HA, Matan M. Anxiety and suicidality in a hospitalized patient with COVID-19 infection. Eur J Case Rep Intern Med. (2020) 7:001651. doi: 10.12890/2020_001651

59. Huang $\mathrm{X}$, Wei F, Hu L, Wen L, Chen K. Epidemiology and clinical characteristics of COVID-19. Arch Iran Med. (2020) 23:268-71. doi: 10.34172/aim.2020.09 
60. Dhama K, Patel SK, Pathak M, Yatoo MI, Tiwari R, Malik YS, et al. An update on SARS-CoV-2/COVID-19 with particular reference to its clinical pathology, pathogenesis, immunopathology and mitigation strategies. Travel Med Infect Dis. (2020) 37:101755. doi: 10.1016/j.tmaid.2020.101755

61. Guan WJ, Ni ZY, Hu Y, Liang WH, Ou CQ, He JX, et al. Clinical characteristics of coronavirus disease 2019 in China. N Engl J Med. (2020) 382:170820. doi: 10.1056/NEJMoa2002032

62. Wang F, Wang H, Fan J, Zhang Y, Wang H, Zhao Q. pancreatic injury patterns in patients with coronavirus disease 19 pneumonia. Gastroenterology. (2020) 159:367-70. doi: 10.1053/j.gastro.2020.03.055

63. Chen N, Zhou M, Dong X, Qu J, Gong F, Han Y, et al. Epidemiological and clinical characteristics of 99 cases of 2019 novel coronavirus pneumonia in Wuhan, China: a descriptive study. Lancet. (2020) 395:507-13. doi: 10.1016/S0140-6736(20)30211-7

64. De Biasi S, Meschiari M, Gibellini L, Bellinazzi C, Borella R, Fidanza L, et al. Marked T cell activation, senescence, exhaustion and skewing towards TH17 in patients with COVID-19 pneumonia. Nat Commun. (2020) 11:3434. doi: 10.1038/s41467-020-17292-4 2020

65. Yang JK, Lin SS, Ji XJ, Guo LM. Binding of SARS coronavirus to its receptor damages islets and causes acute diabetes. Acta Diabetol. (2010) 47:1939. doi: 10.1007/s00592-009-0109-4

66. Ding Y, He L, Zhang Q, Huang Z, Che X, Hou J, et al. Organ distribution of severe acute respiratory syndrome (SARS) associated coronavirus (SARS$\mathrm{CoV}$ ) in SARS patients: implications for pathogenesis and virus transmission pathways. J Pathol. (2004) 203:622-30. doi: 10.1002/path.1560

67. Coronaviridae Study Group of the International Committee on Taxonomy of Viruses. The species severe acute respiratory syndrome-related coronavirus: classifying 2019-nCoV and naming it SARS-CoV-2. Nat Microbiol. (2020) 5:536-44. doi: 10.1038/s41564-020-0695-Z

68. Kucirka LM, Lauer SA, Laeyendecker O, Boon D, Lessler J. Variation in false-negative rate of reverse transcriptase polymerase chain reaction-based SARS-CoV-2 tests by time since exposure. Ann Intern Med. (2020) 173:2627. doi: 10.7326/M20-1495

69. Roschewski M, Lionakis MS, Sharman JP, Roswarski J, Goy A, Monticelli MA, et al. Inhibition of Bruton tyrosine kinase in patients with severe COVID-19. Sci Immunol. (2020) 5:eabd0110. doi: 10.1126/sciimmunol.abd0110

70. Crayne CB, Albeituni S, Nichols KE, Cron RQ. The immunology of macrophage activation syndrome. Front Immunol. (2019) 10:119. doi: 10.3389/fimmu.2019.00119

71. Buja LM, Wolf DA, Zhao B, Akkanti B, McDonald M, Lelenwa L, et al. The emerging spectrum of cardiopulmonary pathology of the coronavirus disease 2019 (COVID-19): Report of 3 autopsies from Houston, Texas, and review of autopsy findings from other United States cities. Cardiovasc Pathol. (2020) 48:107233. doi: 10.1016/j.carpath.2020.107233

72. Guo H, Callaway JB, Ting JP. Inflammasomes: mechanism of action, role in disease, and therapeutics. Nat Med. (2015) 21:677-87. doi: 10.1038/nm.3893

73. Strowig T, Henao-Mejia J, Elinav E, Flavell R. Inflammasomes in health and disease. Nature. (2012) 481:278-86. doi: 10.1038/nature10759

74. El Kasmi KC, Qualls JE, Pesce JT, Smith AM, Thompson RW, HenaoTamayo M, et al. Toll-like receptor-induced arginase 1 in macrophages thwarts effective immunity against intracellular pathogens. Nat Immunol. (2008) 9:1399-406. doi: 10.1038/ni.1671

75. Haskó G, Pacher P. Regulation of macrophage function by adenosine. Arterioscler Thromb Vasc Biol. (2012) 32:8659. doi: 10.1161/ATVBAHA.111.226852

76. Ryzhov S, Zaynagetdinov R, Goldstein AE, Novitskiy SV, Dikov MM, Blackburn MR, et al. Effect of $\mathrm{A} 2 \mathrm{~B}$ adenosine receptor gene ablation on proinflammatory adenosine signaling in mast cells. J Iimmunol. (2008) 180:7212-20. doi: 10.4049/jimmunol.180.11.7212

77. Fredholm BB, Zhang Y, van der Ploeg I. Adenosine A2A receptors mediate the inhibitory effect of adenosine on formyl-Met-Leu-Phe-stimulated respiratory burst in neutrophil leucocytes. Naunyn Schmiedebergs Arch Pharmacol. (1996) 354:262-7. doi: 10.1007/BF00171056

78. Gessi S, Varani K, Merighi S, Leung E, Mac Lennan S, Baraldi PG, et al. Novel selective antagonist radioligands for the pharmacological study of A(2B) adenosine receptors. Purinergic Signal. (2006) 2:5838. doi: 10.1007/s11302-006-9019-x

79. Amisten S, Braun OO, Bengtsson A, Erlinge D. Gene expression profiling for the identification of G-protein coupled receptors in human platelets. Thromb Res. (2008) 122:47-57. doi: 10.1016/j.thromres.2007.08.014

80. Wu C, Chen X, Cai Y, Xia J, Zhou X, Xu S, et al. Risk factors associated with acute respiratory distress syndrome and death in patients with coronavirus disease pneumonia in Wuhan, China. JAMA Intern Med. (2019) 180:93443. doi: 10.1001/jamainternmed.2020.0994

81. Csóka B, Selmeczy Z, Koscsó B, Németh ZH, Pacher P, Murray PJ, et al. Adenosine promotes alternative macrophage activation via $\mathrm{A} 2 \mathrm{~A}$ and $\mathrm{A} 2 \mathrm{~B}$ receptors. FASEB J. (2012) 26:376-86. doi: 10.1096/fj.11-190934

82. Ryzhov S, Goldstein AE, Matafonov A, Zeng D, Biaggioni I, Feoktistov I. Adenosine-activated mast cells induce IgE synthesis by B lymphocytes: an A2B-mediated process involving Th2 cytokines IL-4 and IL-13 with implications for asthma. J Immunol (Baltimore, Md.: 1950). (2004) 172:772633. doi: 10.4049/jimmunol.172.12.7726

83. Roth $\mathrm{S}$, Hackert T. Adenosine in pancreatic cancer: emerging combination therapies. EBioMedicine. (2019) 48:20-1. doi: 10.1016/j.ebiom.2019.09.030

84. Abouelkhair MA. Targeting adenosinergic pathway and adenosine A2A receptor signaling for the treatment of COVID-19: a hypothesis. Med Hypotheses. (2020) 144:110012. doi: 10.1016/j.mehy.2020.110012

85. Kim J, Shin W. How to do random allocation (randomization). Clin Orthop Surg. (2014) 6:103-9. doi: 10.4055/cios.2014.6.1.103

86. Hendry BM, Stafford N, Arnold AD, Sangwaiya A, Manglam V, Rosen $\mathrm{SD}$, et al. Hypothesis: pentoxifylline is a potential cytokine modulator therapeutic in COVID-19 patients. Pharmacol Res Perspect. (2020) 8:e00631. doi: 10.1002/prp2.631

87. Maldonado V, Hernandez-Ramírez C, Oliva-Pérez EA, Sánchez-Martínez CO, Pimentel-González JF, Molina-Sánchez JR. Pentoxifylline decreases serum LDH levels and increases lymphocyte count in COVID-19 patients: results from an external pilot study. Int Immunopharmacol. (2021) 90:107209. doi: 10.1016/j.intimp.2020.107209

88. Reid PG, Watt AH, Routledge PA, Smith AP. Intravenous infusion of adenosine but not inosine stimulates respiration in man. Br J Clin Pharmacol. (1987) 23:331-8. doi: 10.1111/j.1365-2125.1987.tb03053.x

Conflict of Interest: The authors declare that the research was conducted in the absence of any commercial or financial relationships that could be construed as a potential conflict of interest.

Copyright (C) 2021 Caracciolo, Correale, Mangano, Foti, Falcone, Macheda, Cuzzola, Conte, Falzea, Iuliano, Morabito, Caraglia, Polimeni, Ferrarelli, Labate, Tescione, D Renzo, Chiricolo, Romano and De Lorenzo. This is an open-access article distributed under the terms of the Creative Commons Attribution License (CC BY). The use, distribution or reproduction in other forums is permitted, provided the original author(s) and the copyright owner(s) are credited and that the original publication in this journal is cited, in accordance with accepted academic practice. No use, distribution or reproduction is permitted which does not comply with these terms. 